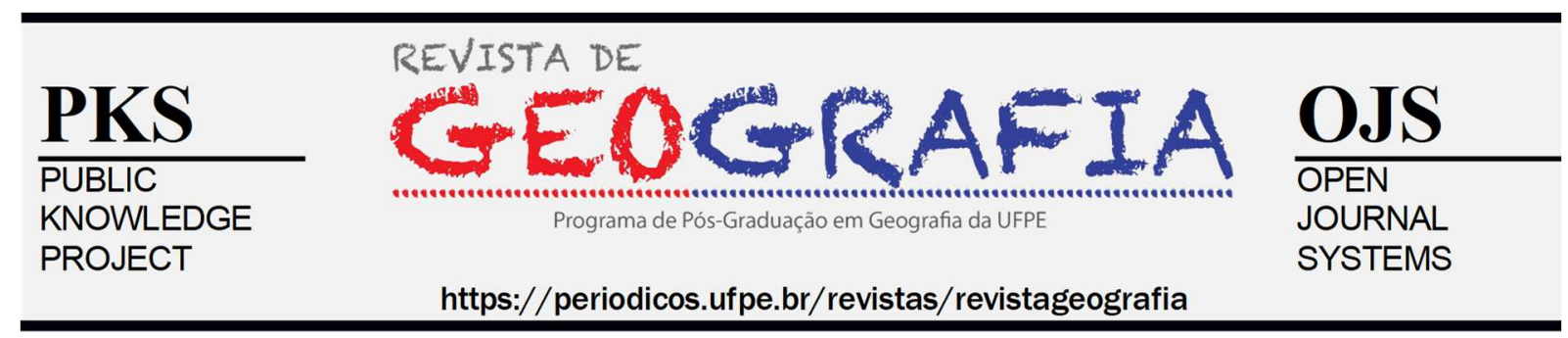

\title{
A REFORMA AGRÁRIA NOS GOVERNOS PÓS REGIME MILITAR NO BRASIL: AVANÇOS E RETROCESSOS
}

\author{
Amanda Júlia de Freitas Mariano ${ }^{1}$, Jodenir Calixto Teixeira ${ }^{2}$ \\ 1 Universidade Federal de Mato Grosso do Sul, E-mail: amandajfmariano@gmail.com. ORCID: \\ https://orcid.org/0000-0003-1129-3649 \\ 2 Universidade Federal de Mato Grosso do Sul, E-mail: jodenirrc@gmail.com. ORCID: \\ https://orcid.org/0000-0002-8226-3685
}

Artigo recebido em 30/05/2020 e aceito em 17/02/2021

\begin{abstract}
RESUMO
O presente trabalho busca analisar e evidenciar os avanços e retrocessos no que tange a reforma-agrária brasileira, nos governos pós-regime militar. A priori fizemos um retrospecto da reforma agrária nos governos da década de 1980 até os dias atuais, incluindo as expectativas para o governode Jair Messias Bolsonaro, eleito e 2018 para a presidência do Brasil. A pesquisa também aborda os processos de resistência frente os retrocessos na reforma agrária brasileira, com a criação da Comissão Pastoral da Terra - CPT, na década de 1970, além da criação do Movimento dos Trabalhadores Rurais Sem Terra MST, na década de 1980, ambos movimentos de resistência ao modelo agrário instaurado no campo brasileiro.
\end{abstract}

Palavras-chave: Reforma-Agrária; Governo; Movimentos Socias.

\section{AGRARIAN REFORM IN POST-MILITARY REGIME GOVERNMENTS IN BRAZIL: ADVANCES AND SETBACKS}

\begin{abstract}
The presente work seeks to analyze and evidence the advances and setbacks with respect to Brazilian agrarian reform, in post-military regime governments. A priori, we made a retrospective of agrarian reform in the governments of the 1980s to the presente day, including expectations for the government of Jair Messias Bolsonaro, elected and 2018 for the presidency of Brazil. The research also adresses the processes of resistance to the setbacks in Brazilian agrarian reform, with the creation of the Pastoral Land Commission - CPT, in the 1970s, in addition to the creation of the Landless Rural Workers MovementMST, in the 1980s, both movements of resistance to the agrarian model established in the Brazilian countryside.
\end{abstract}

Keywords: Land reform; Government; Social Movements. 


\title{
INTRODUÇÃO
}

A reforma agrária, no Brasil, sempre foi relegada a planos secundários, não havendo uma política agrária visando uma melhor distribuição de terras, em um país marcado historicamente pela concentração fundiária. Assim, essa temática sempre chamou a atenção dos pesquisadores nessa área, surgindo importantes abordagens que desdobraram em significativos trabalhos acadêmicos/científicos.

Na Geografia, especialmente na agrária, as discussões se dão em torno da busca pelo entendimento de processos e fatores que abarcam essa questão, desde abordagens em um espaço maior (país ou estado) até em espaços menores, como dos assentamentos. Ambos são relevantes e contribuem para uma análise sob a ótica científica do cenário agrário do país

Assim, esse artigo originou-se a partir das reflexões realizadas na monografia de graduação, defendida junto à Universidade Federal de Mato Grosso do Sul (UFMS) câmpus de Três Lagoas (CPTL), intitulada "Assentamento 20 de Março em Três Lagoas-MS: luta e resistência”. O objetivo principal desse texto é apresentar uma reflexão sobre a realização da reforma agrária no Brasil, no período posterior ao regime militar, identificando os avanços e retrocessos.

\section{Os (des)caminhos da reforma agrária no Brasil entre as décadas de 1980 e 2010}

A partir da década de 1980, houve maiores movimentos de lutas pela terra, fortalecidos pela criação do Movimento dos Trabalhadores Rurais Sem Terra (MST) e o apoio da igreja católica.

\begin{abstract}
O movimento dos trabalhadores Rurais Sem Terra, também conhecido como Movimento dos Sem Terra ou MST, é fruto de uma questão agrária que é estrutural e histórica no Brasil. Nasceu da articulação das lutas pela terra, que foram retomadas a partir do final da década de 70, especialmente na região Centro-Sul do país e, aos poucos, expandiu-se pelo Brasil inteiro. O MST teve sua gestação no período de 1979 a 1984, e foi criado formalmente no Primeiro Encontro Nacional de Trabalhadores Sem Terra, que se realizou de 21 a 24 de janeiro de 1984, em Cascavel, no estado do Paraná. Hoje o MST está organizado em 22 estados, e segue com os mesmos objetivos definidos neste Encontro de 84 e ratificados no I Congresso Nacional realizado em Curitiba, em 1985, também no Paraná: Lutar pela Terra, pela Reforma Agrária e pela construção de uma sociedade mais justa, sem explorados e exploradores (CALDART, 2001, p.207).
\end{abstract}

O MST foi criado na época em que o Brasil estava saindo da ditadura militar, período este em que os movimentos sociais de diversos segmentos sofreram várias formas de repressão. Contudo, a década de 1980 representa um momento de esperança 
para os movimentos sociais, pois com o fim da ditadura militar, se inicia um momento de abertura política no país.

Com maior participação política, devido ao fim da Ditadura Militar (década de 1980) e consequente redemocratização do Brasil, os movimentos sociais trouxeram à tona questões que até então permaneceram "silenciadas". No Brasil, um dos temas ou questão social de mais larga permanência histórica é, indubitavelmente, o problema do "monopólio da terra" (BANNEART, 2008, p.1).

Na luta pela reforma agrária, Caldart (2001) destaca a radicalidade do MST como frente de resistência; a ocupação de latifúndios é uma das principais formas de luta do movimento, pois dessa maneira as suas ações se tornam explícitas ao país.

Os acampamentos às margens de rodovias sempre foram a marca registrada do MST, pois essa forma de luta e resistência foi a única que sempre se mostrou eficaz para a realização da reforma agrária.

Os movimentos sociais foram de extrema importância para as mudanças que ocorreram até os dias atuais na estrutura agrária brasileira. Além do MST, outro movimento que se destacou, na década de 1980, na luta pelos trabalhadores do campo, foi o apoio recebido da igreja católica por meio a Comissão Pastoral da Terra (CPT), criada em junho de 1975, em plena ditadura militar, porém suas ações só ganharam destaque a partir de 1980 .

A CPT foi criada com o intuito de denunciar a grave situação dos trabalhadores rurais, posseiros e peões que trabalhavam em situações análogas à escravidão, em especial, na região amazônica. De modo geral, a CPT buscava a organização dos trabalhadores do campo.

Bannwart (2008) demonstra a importância da CPT e como essa comissão foi amadurecendo internamente, pois no inicio a atenção da CPT era voltada para a Amazônia e para a discussão de distribuição igualitária de terras. Mas, com o processo de transformação interna, a Comissão Pastoral da Terra passou a se atentar para questões ambientais, culturais, além dos direitos humanos.

Nesse cenário de luta pela terra nos últimos anos da ditadura militar, sob o governo João Figueiredo, aconteceu a aprovação da proposta de reforma agrária do Congresso Nacional dos Trabalhadores Agrícolas (CONTAG). No congresso foram apresentadas considerações e proposições na tentativa de concretude de reforma agrária. A proposta tratava desde às decepções que os trabalhadores sofriam com as expectativas frustradas de uma reforma agrária, considerando a promulgação do Estatuto da Terra, e 
perpassava pela exigência de execução da reforma agrária pelos órgãos responsáveis, evidenciando a distribuição de terra a partir de uma visão social. A proposta pontuava a distribuição de terras, a posse e proteção possessória, arrendamento e parceria, o funcionamento da justiça e finalizava com a questão da desapropriação por utilidade pública (STÉDILE, 2005).

Com o fim da ditadura militar e o início do período da Nova República, foi eleito, por eleição indireta, Tancredo Neves do Partido do Movimento Democrático Brasileiro (PMDB). Todavia, o então presidente morreu antes de assumir o poder e, em seu lugar, assumiu José Ribamar de Araújo Costa, mais conhecido como José Sarney, em 15 de março de 1985.

No governo de José Sarney, entre 15 de março de 1985 e 15 de março de 1990, houve a criação do Primeiro Plano Nacional de Reforma Agrária (I PNRA), para diminuir a concentração de terras e as desigualdades decorrentes desta concentração. Mas, de acordo com Rocha (2008), a proposta do plano foi mudada diversas vezes para atender ao interesse dos latifundiários, entretanto, o número de ocupações aumentou gradativamente com a atuação do MST. O autor ressalta que no governo Sarney não foram assentadas nem $10 \%$ do proposto no I PNRA.

O governo sucessor de José Sarney foi Fernando Collor de Mello, que governou no período de 15 de março de 1990 a 29 de dezembro de 1992, do Partido da Reconstrução Nacional (PRN). No curto período de governo, o que mais se fez foi um descaminhar da reforma agrária. Coelho (2017) afirma que Collor foi o pior presidente para a reforma agrária, pois era visto como representante da burguesia, dos latifundiários e dos setores ligado à agricultura capitalista.

Fernando Collor tinha histórico na vida política que antecedeu a sua candidatura presidencial, pois, entre 1979-1982, foi prefeito de Maceió - AL. Ao assumir o governo os anseios do MST acerca do novo presidente se concretizaram. A repressão contra os movimentos sociais foi intensa, inclusive com o aval do governo para as prisões que ocorreram. Assim, o governo de Fernando Collor de Mello foi ainda mais desastroso no que tange a reforma agrária, em relação ao governo anterior.

De acordo com Rocha (2008), no governo Collor, o MST sofreu duras repressões, desde prisão de lideranças até ameaças, na intenção de coibir novos acampamentos. 
Collor causou danos aos movimentos sociais, dentre eles estavam: a aliança entre Fernando Collor e ruralistas; as repressões permitidas pelo governo ao sem-terra; os despejos violentos, assassinatos e prisões arbitrarias. Tudo isso caracterizou uma contrarreforma agrária. Contudo, em 29 de dezembro de 1992, o então presidente renuncia à presidência após ser afastado por um processo de impeachment.

De acordo com o Coelho (2017), a renúncia de Fernando Collor de Mello foi um suspiro para o MST, um fio de esperança que aparecia em meio a um cenário de tanta repressão aos movimentos sociais, que culminaram num descaminhar da reforma agrária. A relação do Governo de Collor e do MST foi marcada por conflitos.

Com a renuncia de Collor, quem assumiu foi seu vice Itamar Augusto Cautiero Franco, popularmente conhecido como Itamar Franco, do Partido Movimento Democrático Brasileiro (PMDB). O novo presidente governou de 29 de dezembro de 1992 a 1 de janeiro de 1995 e foi o primeiro a dialogar com os movimentos sociais para a execução de reforma agrária. Rocha (2008) salienta que foi neste governo que diminuiu drasticamente o número de repressões aos movimentos sociais.

Foi a partir do governo de Itamar Franco que os movimentos sociais tiveram um folêgo, depois de tanta repressão e violência causada pelo governo anterior. Entre 1992 a 1994 a reforma agrária entra na pauta do governo, porém sem os avanços esperados

Neste contexto de novas perspectivas para os movimentos sociais, Pereira (2015, p. 309) afirma:

[...] o governo Itamar (1992-94] fez uma inflexão no tratamento dado aos movimentos sociais do campo. Pela primeira vez um presidente da Republica se reuniu com representantes do Movimento dos Trabalhadores Rurais Sem Terra (MST), reconhecendo a organização como interlocutor legítimo. Pessoas com trânsito e credibilidade entre movimentos sociais foram nomeados para a direção do INCRA no inicio de 1993 (STÉDILE e FERNANDES, 1999; MEDEIROS, 2002). Além disso, com a aprovação da Lei Agrária em maio do mesmo ano, os modestos dispositivos constitucionais sobre reforma agrária foram regulamentados, viabilizando a realização de desapropriações. O tema voltou a ter algum espaço na agenda governamental, tanto pela pressão de movimentos sociais como pela sua associação com o combate à fome. Porém, com a implantação do programa de estabilização monetária (Plano Real), pressões políticas variadas dentro e fora do governo minaram a execução do limitado programa de assentamentos.

Ao se encerrar o mandato de Itamar Franco, inicia-se o do próximo presidente eleito democraticamente, Fernando Henrique Cardoso, do Partido da Social Democracia Brasileira (PSDB). O governo de Fernando Henrique durou 8 anos, contando com a 
reeleição, de 1 de janeiro de 1995 a 1 de janeiro de 2003. Assim como no governo de José Sarney, o governo de FHC não era bem visto diante dos olhos das lideranças políticas dos movimentos sociais voltados para o campo, a exemplo o MST. De acordo com Coelho (2016) o governo do Presidente Fernando Henrique Cardoso foi uma continuidade do regime militar, na questão agrária, desse modo, o plano de reforma agrária que o governo assumiu foi devido às pressões dos movimentos sociais do campo.

Nesse sentido o autor continua:

Embora o tema reforma agrária estivesse nos programas políticos de FHC (eleições de 1994 e de 1998), a reforma agrária, em seus dois governos, não foi tratada como prioridade e nem esteve inserida dentro de uma política de desenvolvimento nacional. Devido às ações dos movimentos sociais do campo e de alguns acontecimentos como a 'Marcha Nacional do MST' 9, em 1997, os massacres de 'Corumbiara' 10, em Rondônia, em 1995, e o de 'Eldorado dos Carajás' 11, no Pará, em 1996, a reforma agrária teve que, no mínimo, entrar em algumas pautas do governo (COELHO, 2016, p.182).

Assim como no período da ditadura militar, o governo de FHC tratou os movimentos sociais do campo de forma repressiva, hora ou outra medindo forças. Um exemplo foram as medidas provisórias criadas pelo governo, afim de barrar as ocupações feitas pelo MST, entre outros movimentos sociais. Nas medidas propunham que as terras só seriam vistoriadas e seria institucionalizada aos assentamentos se não houvesse ocupações.

Num misto de coerção o consenso a política agrária de FHC atuou numa dupla direção: reduzir a reforma agrária à implantação de assentamentos rurais e fortalecimento da agricultura familiar e, ao mesmo tempo, exercer o controle dos conflitos pela adoção de medidas de caráter repressivo. Em 2001, criou duas medidas provisórias: uma em que determinava o não assentamento das famílias que participassem das ocupações de terra; outra que determinava a não vistoria das terras ocupadas por dois anos, quando ocupadas uma vez e por quatro anos quando ocupadas mais de uma vez. O resultado dessas medidas se fez sentir no refluxo observado nas ações de ocupação em todo o país no período em questão (BOTELHO, 2009, p.2).

Nesse sentido, Rocha (2008, p. 49), atenta para a diminuição do número de ocupações a partir da criação da Medida Provisória 2109-52, criada em 24 de maio de 2001, que "impede a desapropriação da área ocupada e tira dos eventuais ocupantes o direito constitucional à reforma agrária. Esta foi uma das formas encontradas pelo governo federal de barrar o crescimento e ações de ocupação”.

No governo FHC, notadamente percebe-se que entre os anos de 1995 a 2000 houve uma redução drástica nos números de famílias assentadas; até o ano de 1998 haviam mais de 83 mil famílias assentadas e, ao chegar nos anos 2000, apenas 39 mil 
famílias são assentadas. Essa redução deixa claro a falta de interesse do governo em realizar a reforma agrária. Verifica-se que todas as medidas em beneficio da reforma agrária, somente aconteceram, mediante pressão dos movimentos sociais.

De acordo com Oliveira (2001), o governo de Fernando Henrique criou diversas estratégias no intuito de fazer pressão nos movimentos sociais, em especial, no MST, desde violência policial até a criação de novos movimentos sociais que não utilizavam a ocupação como meio de luta. Por exemplo, surgiram novos movimentos sociais que não usavam os acampamentos como forma de luta e pressão ao governo; o objetivo era o enfraquecimento do MST.

A partir dessa análise percebemos que a relação dos movimentos sociais do campo, em especial o MST, com o governo de Fernando Henrique Cardoso foi uma relação conflituosa, com intensa repressão.

O sucessor de Fernando Henrique Cardoso na presidência foi o ex metalúrgico Luiz Inácio Lula da Silva. Lula disputava as eleições presidenciais desde 1989 e o carro chefe de todas as suas campanhas eram as propostas que abarcavam todo o cenário agrário, incluindo: políticas agrícolas para segurança alimentar, políticas para a produção, políticas de desenvolvimento agroindustrial, política de emprego e relações de trabalho, previdência social rural, políticas de desenvolvimento rural e de combate à pobreza e políticas agrárias do Partido dos Trabalhadores, referente às Políticas de Abastecimento e Ações Emergenciais de Combate à Fome. A campanha do PT foi no âmago do trabalhador rural que tanto anseia por um pedaço de terra para poder se reproduzir socialmente e culturalmente (STÉDILE, 2005).

O Partido dos Trabalhadores em seu discurso de campanhas à Presidência da República no ano de 1994 colocou as políticas agrícolas do partido como uma forma de fazer as mudanças tão desejadas pelo homem do campo e da cidade, dando esperanças principalmente ao camponês de ter uma forma de sobrevivência na terra onde nasceu ou até mesmo de não ter de compor a massa de desempregados das cidades. E mais uma vez em seu discurso, o PT deu ênfase à reforma agrária acompanhada de uma reforma nas políticas agrícolas dando condições ao trabalhador rural, segundo seu discurso, de ter onde produzir, como produzir através de financiamentos e técnicas respeitando a peculiaridade de cada região brasileira. Onde produzir, como produzir através de financiamentos e técnicas respeitando a peculiaridade de cada região brasileira (SANTOS, 2013, p. 9).

Dentro do quadro de proposta do programa petista havia enfoque na responsabilidade com o meio ambiente, aos direitos indígenas e também aos quilombolas. Mas mesmo com uma campanha focada nas questões sociais e ambientais, 
assim como na campanha anterior, o partido dos trabalhadores não obteve êxito na disputa presidencial.

Também, em 1998, o partido dos trabalhadores tentou, por mais uma vez, disputar a presidência do Brasil, mas não obteve sucesso. Entretanto, em 2002, pela primeira vez o Partido dos Trabalhadores ascendeu a presidência com 61,27\% dos votos válidos. Entretanto, com a vitória nas eleições presidenciais de 2002, o partido mudou seu programa de governo referente à questão agrária, voltando mais à Política Comercial.

\begin{abstract}
Seu compromisso de campanha em relação às políticas agrárias em 2002 não se inicia com o tema Reforma Agrária, como nas últimas três disputas eleitorais a Presidência da Republica, e sim Política Comercial, onde o PT vai destacar a política comercial da seguinte forma: "a política comercial será organizada a partir de dois grandes objetivos: a defesa da agricultura brasileira e a promoção das exportações com maior valor agregado. $\mathrm{O}$ governo Lula adotara políticas rigorosamente sob o abrigo do espectro jurídico acordado junto a OMC e ao MERCOSUL (SANTOS, 2013, p.14).
\end{abstract}

Os movimentos sociais nutriam expectativas no governo Lula, pois em todas as campanhas para disputas eleitorais a reforma agrária era destaque. A importância de mudança da estrutura fundiária brasileira para uma redistribuição de terras mais justas era o lema do PT, mas, ao se tornar presidente, Lula mudou o plano de governo para Desenvolvimento Rural, com uma política assistencialista, deixando desapontados milhões de trabalhadores que sonhavam com justiça através da nova gestão (STÉDILE, 2005).

Em realidade, no governo do PT, o número de assentamento criados foi menor que no governo anterior, porém houve o fortalecimento de assentamentos já existentes e também dos novos, ou seja, no governo Lula foi presado a qualidade dos assentamentos, dando condições para o pequeno produtor permanecer na terra. Entretanto, Engelmann et al (2012) afirma que o número de áreas desapropriadas foi em detrimento das pressões dos movimentos sociais. Com uma política de caráter assistencialista e com políticas compensatórias o governo contou com programas como o FOME ZERO, que tinha como intuito a soberania alimentar, porém, a reforma agrária seria o caminho para uma agricultura mais produtiva, garantindo o extermínio da pobreza e redistribuição (justa) de terras.

Como dito anteriormente o projeto de reforma agrária do PT, defendido desde 1989, mudou em 2002 quando o partido ganhou a disputa presidencial. O que era para ser uma reforma agrária mudou para programa de combate à pobreza. E o então 
presidente Luiz Inácio Lula da Silva criou dois programas opostos de agricultura: de um lado a consolidação dos assentamentos já existentes, ressaltando que não houve a destruição dos grandes latifúndios como proposto nos planos de governo anteriores e, de outro lado, aumento nos investimentos financeiros e incentivos para a agricultura capitalista, o agronegócio.

Engelmann et al (2012) afirma que no primeiro mandato Lula houve uma maior concessão de apoio aos grandes proprietários de terras, contrariando os movimentos sociais do campo, apesar das políticas realizadas também para o pequeno produtor.

Como já dito, no governo Lula houve uma política compensatória, com incentivos para agricultura familiar na intenção de extinguir a pobreza, enquanto havia grandes investimentos para o agronegócio, ao mesmo tempo. A verdadeira reforma agrária com desconcentração fundiária e desapropriação de latifúndios não ocorreu no governo petista. Dessa forma as pressões dos movimentos sociais voltam no segundo mandado do candidato, concretizando a criação de novos acampamentos, mas não com a mesma intensidade que nos governos anteriores.

Lula tentou conciliar dois modelos agrícolas: de um lado, criando uma política de assentamentos e incentivo à agricultura familiar com produção de alimentos para o programa de combate a pobreza; e de outro, injetando investimentos econômicos no agronegócio, para produção em grande escala e exportação. As duas políticas acabaram reforçando a predominância econômica do grande latifúndio, sob a égide do agronegócio ou grande capital deste setor (nacional e, sobretudo, estrangeiro), mantendo intacta a estrutura agrária brasileira pelo menos desde a década de 1960 (ENGELMANN et al, 2012, p. 8).

Contudo é importante salientar que, mesmo tendo privilegiado em seu governo a agricultura capitalista, foi com o presidente Lula que houve uma melhora significativa na vida do pequeno produtor rural. A partir da implementação melhoria de políticas como: PRONAF - Programa Nacional de Fortalecimento da Agricultura Familiar, o programa luz para todos, a educação no campo, o PAA - Programa de Aquisição de Alimentos, o PNAE - Programa Nacional de Alimentação Escolar, que permitem ao pequeno produtor a sua permanência no campo.

Ainda no governo petista, mas dessa vez sob o comando da presidenta Dilma Rousseff, no período de 1 de janeiro de 2011 a 31 de agosto de 2011, mais uma vez a questão agrária não foi priorizada e reduziu ainda mais as desapropriações de terra. No primeiro mandato de Dilma, o número de famílias assentadas é menor que o registrado 
por Luiz Inácio Lula da Silva em seu primeiro e em seu segundo mandato e por Fernando Henrique Cardoso em cada um de seus dois governos.

TABELA 1: PANORAMA DA REFORMA AGRÁRIA SEGUNDO DECRETOS DE DESAPROPRIAÇÃO (PERÍODO SARNEY ATÉ ROUSSEFF)

\begin{tabular}{l|l}
\hline \multicolumn{2}{c}{ DESAPROPRIAÇÃO (PERIODO SARNEY ATE ROUSSEFF) } \\
\hline Sarney (1985-1989) & Decretos de desapropriação \\
\hline Fernando Collor (1990-1992) & 748 \\
\hline Itamar Franco (1992-1994) & 28 \\
\hline Fernando Henrique Cardoso (1995-2002) & 238 \\
\hline Luiz Inácio Lula da Silva(2003-2011) & 3.532 \\
\hline Dilma Rousseff (2011-até hoje) & 1990 \\
\hline TOTAL & 94 (até outubro de 2013) \\
\hline
\end{tabular}

Fonte: SindPFA (2013), INCRA (2013b). ORG. Iris Cecilia Ordóñez Guerrero e Sonia Maria Pessoa Pereira Bergamasco.

A tabela 1 mostra o número de decretos de desapropriações no governo Dilma, até o ano de 2013, que totalizava 94 desapropriações. Em 2016 foram assentadas, nesse governo, 1686 famílias. No governo da então presidente o discurso era de que o governo iria dar prioridade para o fortalecimento dos assentamentos já existentes, melhorando a qualidade de vida dos assentados e da agricultura familiar. Porém, em 2016, a presidente eleita democraticamente com a maior porcentagem de votos válidos sofreu impeachment pelo crime de "pedaladas fiscais" (termo que se refere a operações orçamentárias realizadas pelo Tesouro Nacional, não previstas na legislação, que consistem em atrasar o repasse de verba a bancos públicos e privados coma intenção de aliviar a situação fiscal do governo em um determinado mês ou ano). No entanto, as acusações feitas não foram comprovadas, o que caracteriza "um golpe" por trás desse processo.

A partir da queda da presidente Dilma Rousseff, assumiu a presidência do país, seu vice Michel Temer, do Partido Movimento Democrático Brasileiro (PMDB). Michel Temer iniciou seu governo em 31 de agosto de 2016 até 31 de dezembro de 2018. Desde quando iniciou o governo Temer, a expectativa dos movimentos sociais era de um governo conservador e fechado para a reforma agrária, contribuindo com maior apoio para o agronegócio. De acordo com o MST, seu projeto de governo foi de encontro com o "aniquilamento da reforma agrária". Inclusive no ano de 2017, no governo Temer, não houve registro do assentamento de famílias. 
Nesse contexto, fica clara a preocupação do MST em relação à reforma agrária no governo Temer, pois o que de fato aconteceu, neste governo, foi uma contrarreforma agrária. Inclusive se igualando ao governo de José Sarney, até então o pior governo da história brasileira, referente a democratização do acesso à terra.

Corroborando para o descaminho de uma reforma agrária, entra em cena o triunfo de Jair Messias Bolsonaro na última eleição para presidente. Mais conhecido como Bolsonaro, faz parte do Partido Social Liberal (PSL).

Antes mesmo de assumir a presidência, Bolsonaro já havia deixado claro sua aversão ao MST, afirmando qual seria o tratamento dados aos movimentos sociais, em especial o MST, durante seu governo. De acordo com o presidente, "invasão" de propriedade urbana ou rural será tipificada como terrorismo, além da liberdade de repressão aos movimentos sociais.

Um dos atos de Jair Bolsonaro que evidenciam o descaso com a reforma agrária foi a nomeação de Luiz Nabhan Garcia para a Secretaria de Assuntos Fundiários do governo federal, órgão responsável pela demarcação de terras e reforma agrária. Luiz Nabhan foi presidente da União Democrática Ruralista (UDR), além de ter sido investigado por ligações com milícias privadas criadas para combater o MST. O presidente também transferiu o Instituto Nacional de Colonização e Reforma Agrária (INCRA) do Ministério da justiça para o Ministério da Agricultura.

O pronunciamento de Jair Messias Bolsonaro, além de suas ações, comprova o seu projeto de contrarreforma agrária, além de seu governo ser em detrimento da agricultura capitalista, o agronegócio. A vitória de Jair Messias Bolsonaro para a presidência foi um golpe para toda a classe de movimentos sociais que reivindicam a redemocratização do acesso à terra, ainda assim, as lideranças dos movimentos sociais já esperavam determinadas posturas do presidente, baseado nos seus discursos quando ele ainda era um candidato.

\section{Considerações finais}

O espaço agrário brasileiro sempre foi palco de conflitos pelo uso da terra, desde sua colonização até o momento atual. Podemos destacar nesse cenário a reinvindicação do movimento dos trabalhadores contra a exploração, a luta dos posseiros contra a expropriação, os indígenas reivindicando a demarcação de suas terras, os pequenos 
produtores atingidos pela construção de hidroelétricas e a luta dos acampados às margens de rodovias nos movimentos de reforma agrária.

Nesse contexto de conflitos pela posse da terra, no Brasil, os trabalhadores do campo se organizam para reivindicar mudanças na estrutura agrária brasileira, exigindo uma reforma agrária, para que a terra cumpra a sua função social.

Com o fim do regime militar no Brasil, esperava-se maiores avanços no processo de realização de uma reforma agrária justa no país, porém, isso não ocorreu, levando à intensificação das ações dos movimentos sociais de luta pela terra e dos conflitos no campo. Não houve a concretização de uma política voltada para essa questão em nenhum dos governos e, cada um deles, tratava essa temática atendendo determinados interesses, que não eram dos trabalhadores.

Numa comparação generalizada, podemos afirmar que de todos os governos brasileiros, posteriores ao regime militar, o que melhor fez para a reforma agrária foi o governo petista de Luiz Inácio Lula da Silva, que embora não tenha assentado tantas famílias, comparado a outros governos, levou em consideração a qualidade dos assentamentos existentes, criando políticas para a permanência destas famílias na terra. O destaque maior de seu governo não foi o número de assentamentos criados e sim a implementação de políticas públicas para atender a agricultura familiar e diminuir as desigualdades no campo.

\section{REFERÊNCIAS}

BANNWART, E. C. A Comissão Pastoral da Terra no Brasil Contemporâneo: Da luta pela Terra À Ecologia, ANPUH, São Paulo, 2008.

BOTELHO, M. A. O reformismo agrário do governo FHC, REVISTA DE POLÍTICAS PÚBLICAS, 2009.

CALDART, R. S. O MST e a formação dos sem-terra: o movimento social como princípio educativo. Estudos Avançados, São Paulo, 2001.

COELHO, F. Reforma Agrária no Governo FHC: perfil, tensões, número de famílias assentadas e áreas obtidas. Diálogos-Revista do Departamento de História e do Programa de Pós-Graduação em História, Dourados, 2016.

COELHO, F. Descaso com a Reforma Agrária e Repressão Contra os Movimentos Sociais: representações do MST sobre Collor (1990-1992). Antíteses, 2017. 
ENGELMANN, S. et al "A Questão Agrária no Brasil: a Política Agrária do Governo Lula e a Relação com o MST'. Revista Eletrônica do CEMOP, 2012.

OLIVEIRA, A. U. de. A longa marcha do campesinato brasileiro: movimentos sociais, conflitos e Reforma Agrária. Estudos avançados, 2001.

PEREIRA, J. M. M Estado e mercado na reforma agrária brasileira (1988-2002), Estudos Históricos, Rio de Janeiro, 2015.

ROCHA, H. F. Análise e mapeamento dos tipos de assentamentos no Brasil: compreender a diversidade e a atualidade da reforma agrária brasileira. Estudo dos assentamentos da região Centro-Sul. Estudo dos assentamentos da região Centro-Sul, Presidente Prudente, 2008.

SANTOS, E. M. As Políticas Agrárias do Partido dos Trabalhadores (1989- 2002). Simpósio ,2013.

STÉDILE, J. P. A questão agrária no Brasil: programas de reforma agrária, 19462003. Bib. Orton IICA/CATIE, 2005. 